\title{
Life Cycle Assessment of Water in Sport Equine Production in Argentina: A Case Study
}

\author{
Mariana M. Vaccaro ${ }^{1,2}$, Alberto García-Liñeiro ${ }^{1}$, Alicia Fernández-Cirelli ${ }^{2,3}$ and Alejandra V. Volpedo ${ }^{2,3, *}$ \\ 1 Cátedra de Salud y Producción Equina, Facultad de Ciencias Veterinarias, Universidad de Buenos Aires, \\ Av. Chorroarín 280, Buenos Aires C1427CWO, Argentina; mvaccaro@fvet.uba.ar (M.M.V.); \\ garcialineiro@fvet.uba.ar (A.G.-L.) \\ 2 Instituto de Investigaciones en Producción Animal (INPA), CONICET-Universidad de Buenos Aires, \\ Av. Chorroarín 280, Buenos Aires C1427CWO, Argentina; afcirelli@fvet.uba.ar \\ 3 Centro de Estudios Transdisciplinarios del Agua (CETA), Facultad de Ciencias Veterinarias, \\ Universidad de Buenos Aires, Av. Chorroarín 280, Buenos Aires C1427CWO, Argentina \\ * Correspondence: avolpedo@fvet.uba.ar
}

Citation: Vaccaro, M.M.;

García-Liñeiro, A.; Fernández-Cirelli, A.; Volpedo, A.V. Life Cycle Assessment of Water in Sport Equine Production in Argentina: A Case Study. Agriculture 2021, 11, 1084. https://doi.org/10.3390/ agriculture11111084

Academic Editor: Peter Tozer

Received: 24 September 2021

Accepted: 29 October 2021

Published: 2 November 2021

Publisher's Note: MDPI stays neutral with regard to jurisdictional claims in published maps and institutional affiliations.

Copyright: (c) 2021 by the authors. Licensee MDPI, Basel, Switzerland. This article is an open access article distributed under the terms and conditions of the Creative Commons Attribution (CC BY) license (https:// creativecommons.org/licenses/by/ $4.0 /)$.

\begin{abstract}
The application of life cycle assessment method (LCA) to animal production is a methodological option to assess the potential impact of products, services, or production processes in a comprehensive way as it considers both the quantity and quality of water in the life cycle approach. In this paper, the water footprint of jumping sport horses' production has been determined using the LCA methodology for the first time ever. The results of this paper show that the production of medium- and high-performance sport horses uses a large amount of water. However, modifications to the diet (type and percentage of oils in the supplement, place of origin of feed, etc.) and in the management and destination of waste (animal box beds) can result in a reduction of the water requirement and the environmental impact of production. This type of studies should be developed in different farms in the future in order to give producers management alternatives that improve the sustainability of productions.
\end{abstract}

Keywords: water; sport equine production; life cycle assessment

\section{Introduction}

The interest in water footprint stems from the acknowledgment that human impact on water systems may be related to human consumption and to the fact that certain issues such as water shortage and contamination may be better understood and managed considering the production and distribution chains in its entirety.

The problem of water is one of the most feasible causes of potential global crisis in the coming decades $[1,2]$.

The United Nations in its sustainable development goals (SDGs) recognizes the water issue as one of the most relevant in the world. This issue is transversal to all the SDGs [3,4].

One of the tools used worldwide is the life cycle assessment method (LCA), applicable to the productive system, which was standardized in accordance with ISO 14046: "Environmental management-Water footprint-principles, requirements and guidelines" (2014). The life cycle approach has proven to be a promising way to analyze the social, economic, and environmental impacts of bio-based products along the whole value chain. This method represents a valuable framework the transdisciplinary nature of which clearly demonstrates the importance of its integration not only with economic models, but also with ecological and social theories $[5,6]$.

This methodological option can assess the potential impact of products, services, or production processes comprehensively, since it considers not only the water quantity but also its quality in the life cycle approach [7-9]. ISO standard 14046 presents another methodological option to the traditional water footprint proposed by Hoekstra [10]. With 
regard to animal production, there are few studies in relation to the water footprint either by traditional assessment of the water footprint [11-14] or by the methodology suggested by the ISO 14046 approach [15]. Equine production in Argentina has never been assessed in any of these aspects.

In equine production water is used straight for horses drinking and for horse bathing and cleaning of facilities (stables). However, the animals also incorporate water indirectly through food consumption. Food composition, particularly, the proportion of concentrates with respect to the feed will determine the amount of water consumed, because a larger amount of water is used in the production of concentrates than in the production of feed [16].

The production of sport horses is expanding, and Argentina is one of the countries that exports animals for equestrian sports.

On the other hand, there are few studies in the world that analyze these aspects in this production and, at most, they focus on animal production only for consumption [17], or on food of animal origin such as milk [18], but not on the production of sport animals.

The aim of this study is to determine, for the first time ever, the water footprint of the production of jumping sport horses.

\section{Materials and Methods}

Based on previous studies $[19,20]$ a sport horses farm in the Province of Buenos Aires was selected as study case. This farm is recognized in the equestrian sector for the performance of both horses and riders. Its productive profile was developed from a survey (Appendix A), as well as regular visits to the farm and the collection of water and box bedding samples. Data on cleaning of facilities, weekly bathing water management and horse activities were also collected. This farm was selected among 26 other farms studied since it holds 50 high- and medium-performance jumping horses, all of which share the same training routine; therefore, veterinary management is the same for all of them with regard to feed, supplementation, and cleaning.

A water life cycle analysis was performed, based on water input and output and its uses for production in accordance with ISO 14046 methodology [21].

\subsection{Functional Units}

The functional units of the LCA studied are the horses (male or female) of high and medium performance.

High-performance horses have the following training daily routine: in the morning, they walk between 20 to $30 \mathrm{~min}$ in a round horse walker or with their trainers holding a rope. In the afternoon, they walk $10 \mathrm{~min}$ and trot for $15 \mathrm{~min}$ with their horseman or horsewoman alternately. After that, they jump over fences in the horse track for $50 \mathrm{~min}$. The fences have different heights, reaching up to $1.70 \mathrm{~m}$. The horses follow the routine mentioned above six days a week.

Medium performance horses have the following training daily rotuine: they walk between 20 to $30 \mathrm{~min}$ in a round horse walker or with their trainers holding a rope. In the afternoon, they walk $10 \mathrm{~min}$ and trot for $15 \mathrm{~min}$ with their horseman or horsewoman alternately. After that, they jump over fences in the horse track for $50 \mathrm{~min}$. The fences have different heights, reaching up to $1.40 \mathrm{~m}$. The horses follow the routine mentioned above three days a week.

\subsection{Inventory Analysis}

Inventory Analysis includes drinking water, water for feed and dietary supplement production, bathing water, and water to clean the boxes (Figure 1). 


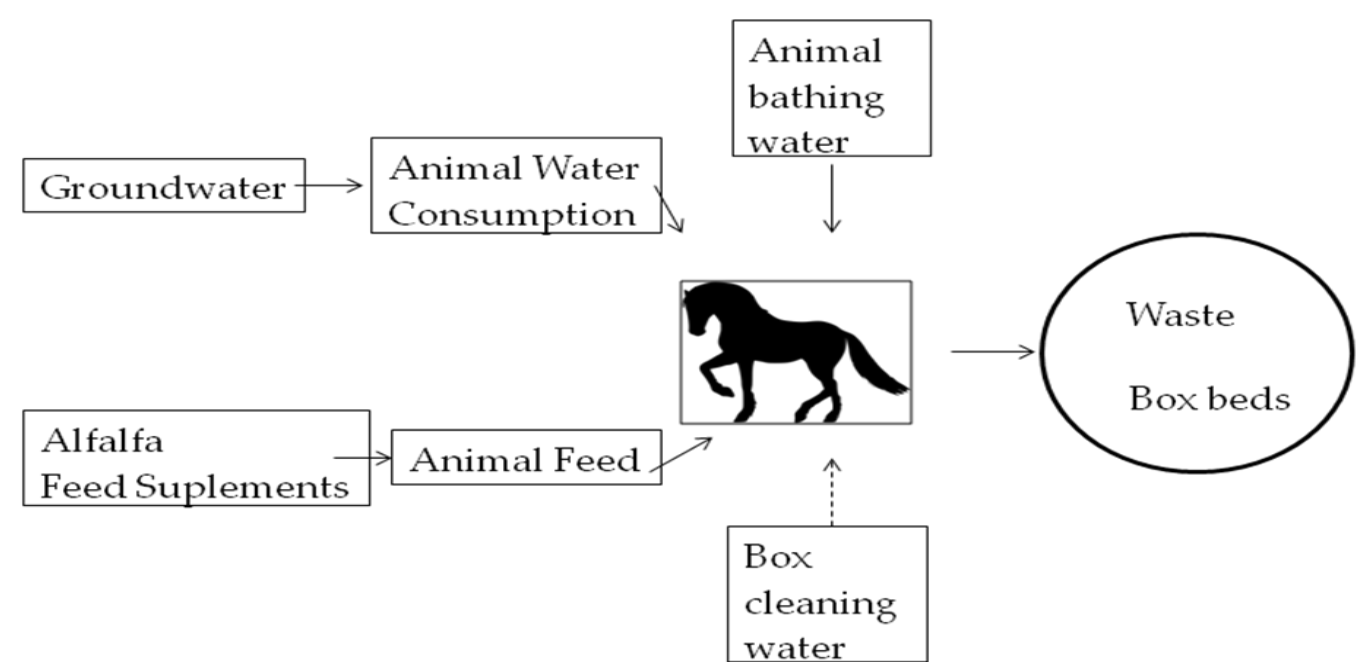

Figure 1. Diagram of water life cycle in this farm. Entire lines: use of direct water. Split lines: indirect use.

Average drinking water consumption for $450 \mathrm{~kg}$. live weight horses actively working (room temperature from $15{ }^{\circ} \mathrm{C}$ to $21^{\circ} \mathrm{C}$ ) is at approximately 54-63 L/animal/days [22] Animal water consumption was thus estimated, and this figure was verified in situ during the regular visits of the professional veterinary to the farm.

Animals were classified according to their training as high- and medium-performance, as in the case of sport equines water consumption is directly related to work intensity. Mares in competition are prevented from getting pregnant; therefore, they are not in full breastfeeding or pregnancy periods in which water consumption might increase.

The quality of the water consumed by the animals was analyzed. The following physicochemical parameters were registered: $\mathrm{pH}$, conductivity $(\mu \mathrm{S} / \mathrm{cm})$ through Hanna HI 9828 (Hanna Instruments, Woomsocket, RI, USA), total hardness (mg/L) determined by ethylenediaminetetraacetic acid (EDTA) titration method chlorides $(\mathrm{mg} / \mathrm{L})$ by the argentometric method and nitrates $(\mathrm{mg} / \mathrm{L})$ by the cadmium reduction method with $\mathrm{HACH}$ DR 890 (Hach Company, Loveland, CO, USA) [23].

An analysis of animal feed as water source was performed considering consumption of hay and concentrates for active sports animals at $1.25 \mathrm{~kg} /$ animal of alfalfa for every $100 \mathrm{~kg}$ of horse weight and at $1 \mathrm{~kg}$ /animal of concentrate for every $100 \mathrm{~kg}$ of horse weight [24]. The water consumption values for each kind of feed were taken from World Food LCA Database [25].

With regard to the amount of animal bathing water it was considered that medium performance equines are bathed three times a week, while high performance animals are bathed every day. The bath is performed with a bucket, and a total of $90 \mathrm{~L}$ per animal was estimated for each bath. During bath in addition to water, shampoo and conditioner with similar characteristics of those used by humans is applied. As to the cleaning of facilities, boxes are washed down twice a week in this farm, using approximately $15 \mathrm{~L}$ of water per box. Each box has an approximate surface of 3 by $4 \mathrm{~m}$ and it is ventilated.

All these water consumption figures for both animal and box cleaning were also verified by the periodic visits of the professional veterinary to the farm and through said survey (Appendix A).

The composition of the wood shavings bed used in the boxes was analyzed with regard to the trace elements present. For this analysis the following elements were selected: $\mathrm{As}, \mathrm{Cd}, \mathrm{Cr}, \mathrm{Ni}$, and $\mathrm{Pb}$. These elements were selected since their presence in large quantities in the water may be harmful to the animals' health [19,26,27]; besides, in Argentina, arsenic is a toxic natural element very often found in ground and surface water [28]. This element comes from the pampean loess and it is present in large quantities in the ground and surface water of the Pampa plains [29]. The $\mathrm{Cr}, \mathrm{Cd}$, and $\mathrm{Pb}$ are of anthropogenic origin. 
Quantification of $\mathrm{As}, \mathrm{Pb}, \mathrm{Cd}$, and $\mathrm{Cr}$ was performed by ICP-OES (inductively coupled plasma-optical emission spectroscopy) using a Perkin Elmer Optima 2000 DV (PerkinElmer Inc., Überlingen, Germany). For the equipment calibration, reference materials from the National Water Research Institute of Canada (NWRI) with certified content of all minor elements were used for calibration, verification, and validation of the analytical method.

With all data collected a water flow chart was developed at the farm and the monthly inputs and outputs were determined, according to the ISO 14046 proposal. Based on this data, recommendations were made in order to minimize consumption of this resource and to improve the farm's environmental profile as a pilot case of equine production in the region.

\section{Results and Discussion}

The water life cycle in this farm follows the following diagram (Figure 1).

The water used in the farm comes from $80 \mathrm{~m}$ deep underground water well. Farm water physicochemical parameters show the following average figures: $\mathrm{pH}$ : 6.81; conductivity: $852 \mu \mathrm{S} / \mathrm{cm}$; total hardness: $213 \mathrm{mg} / \mathrm{L}$; chlorides: $28 \mathrm{mg} / \mathrm{L}$; and nitrates: $2.5 \mathrm{mg} / \mathrm{L}$. These figures show that farm water is of relatively good quality although nitrates level is over guideline levels proposed by Canadian Environmental Quality Guidelines (CEME) $(<1 \mathrm{mg} / \mathrm{L})$ and United States Environmental Protection Agency (USEPA) $(<1 \mathrm{mg} / \mathrm{L})$ [30,31]. Farm water quality is appropriate with regard to other horse farms in the region and is consistent with the results found by Vaccaro et al. [20].

Direct water consumption is intended for drinking, animal bathing and box cleaning. The estimated amount of water consumed monthly by high performance animals $(N=30)$ is of $56,700 \mathrm{~L}$ and by medium performance animals $(N=20)$ is of $32,400 \mathrm{~L}$.

Monthly water consumption by animals, water for animal bathing and box cleaning is shown in Table 1.

Table 1. Monthly water consumption (L) by animals drinking, water for animal bathing, and water for box cleaning. $N$ : samples number.

\begin{tabular}{lccccc}
\hline \multirow{2}{*}{ Activity } & Intensity & $N$ & \multicolumn{3}{c}{ Monthly Water Consumption (L) } \\
& Animal & Animal & Box \\
Bathing & Cleaning \\
\hline \multirow{3}{*}{ Jumping } & $\begin{array}{c}\text { Medium } \\
\text { performance } \\
\text { High } \\
\text { performance }\end{array}$ & 20 & $32,400 \pm 3300$ & $21,600 \pm 1900$ & $2400 \pm 200$ \\
& 30 & $56,700 \pm 4900$ & $75,600 \pm 7300$ & $3600 \pm 350$ \\
\hline
\end{tabular}

Monthly bathing water consumption in high performance animals is higher because they are bathed daily. Boxes are cleaned weekly; however, the difference lies in the number of boxes assigned to each animal according to its type of activity. Disinfectant is used to clean boxes. These products must be biodegradable so as to minimize the environmental impact of the animal bathing process.

\section{Impact Assessment}

With regard to water indirectly incorporated in equine production through feed, it should be considered that farm horses weigh $500 \mathrm{~kg}$ each on average; therefore, each one consumes approximately $6.25 \mathrm{~kg}$ of hay daily.

Alfalfa is the main component of the hay used for feed of the horses studied and it takes approximately from 1100 to $1550 \mathrm{~mm}$ of water annually to grow, with a yield of 2000 tonnes per hectare [32]. Even though Argentina is the second world alfalfa producer, the provinces of Santiago del Estero and Córdoba, where the hay consumed by the horses studied is produced, have shown a significant reduction in the amount of rainfall over the last 60 years [33]. In these areas, hay crops are unirrigated and depend only on rainfall which is approximately $850 / 940 \mathrm{~mm}$ yearly [33]. The amount of water necessary to produce 
a ton of alfalfa in Argentina is approximately $830 / 880 \mathrm{~m}^{3}$ [34], while in other regions in the world it is higher; for example, in the United States of America $\left(1432 \mathrm{~m}^{3}\right)$ or in New Zealand $\left(970 \mathrm{~m}^{3}\right)$ [35]. This fact offers an advantage not only due to the lower amount of water used for alfalfa production, but also to the lower transport costs, since the crop is grown in Argentina.

Feed supplementation of the farm animals consists in oats and oil energy concentrates (50-50\% mix of corn and sunflower oils). The daily amount per animal is $5 \mathrm{~kg}$ of oats, and $80 \mathrm{~cm}^{3}$ of the oil mix.

Oat farming requires between 500 and $800 \mathrm{~mm}$ of water per hectare, corn (dry grain) between 330 and $412 \mathrm{~mm}$, and sunflower $500 \mathrm{~mm}[36,37]$. Additionally, water is used in the production process of the supplement oils at an estimated $2575 \mathrm{~m}^{3} /$ ton for corn oil and $6792 \mathrm{~m}^{3} /$ ton for sunflower oil [38]. It should be noted that the reduction in sunflower oil added would further reduce the amount of water associated to this supplement. For example, if only corn oil were used in the diet supplementation, the amount of water used monthly would be reduced approximately 3 times in comparison with the mix of two oil types. As a consequence, global water consumption in production would be reduced.

With regard to the analysis of the trace elements present in the box beds the following figures were found: $0.55 \mu \mathrm{g} / \mathrm{g} \mathrm{Cd}, 0.87 \mu \mathrm{g} / \mathrm{g} \mathrm{Cr}, 0.80 \mu \mathrm{g} / \mathrm{g} \mathrm{Ni}$, and $0.61 \mu \mathrm{g} / \mathrm{g} \mathrm{Pb}$; the value for As $(<0.40 \mu \mathrm{g} / \mathrm{g})$ remained below detection levels.

The animals rest in boxes with wood shaving beds for $10 \mathrm{~h}$ a day. Beds are removed daily, they are laid in an outdoors space on the ground, usually called "virutero". This waste receives rainfall (from $65 \mathrm{~mm}$ in winter to $125 \mathrm{~mm}$ in summer, 2021). It should also be noted that the northern area of the Province of Buenos Aires has shown an upward trend in the amount of rainfall over the last 60 years [33]. This might worsen the quality of underground water, and indirectly affect the water source for farm consumption as well. Therefore, it is relevant that animal bedding waste be placed in an adequately waterproofed and roofed area in order to minimize the potential for leaching of trace elements and other compounds to underground water.

The results of this paper show for the first time ever that the production of medium- and high-performance sports equines uses a large amount of water (Figure 1 and Tables 1 and 2).

Table 2. Monthly water consumption (L) for animal feed. $N$ : samples number.

\begin{tabular}{ccccc}
\hline Activity & Intensity & $N$ & \multicolumn{2}{c}{ Monthly Water Consumption (L) } \\
Alfalfa & $\begin{array}{c}\text { Feed Supplements } \\
\text { (Mix 50-50\%) }\end{array}$ \\
\hline \multirow{2}{*}{ Jumping } & Medium performance & 20 & $\cong 3.3 \times 10^{6}$ & $\cong 342 \times 10^{6}$ \\
& High performance & 30 & $\cong 4.9 \times 10^{6}$ & $\cong 539 \times 10^{6}$ \\
\hline
\end{tabular}

However, modifications in diet management (type and percentage of oils in the supplement, place of origin of hay, etc.) and in waste management and disposal, such as horse bedding, might reduce the water requirements and the environmental impact of the production.

In the future, this type of study should be developed in different farms in order to provide farmers with management alternatives to improve sustainability in their production processes.

\section{Conclusions}

The LCA methodology in the production of sport horses allows the identification of production hot spots in relation to water consumption and environmental impacts, which may be modified to increase the environmental sustainability of production processes.

Producers, farm workers, and veterinarians have a key role in the sustainability of sport equine production, since the decisions related to animals' diet management, and the purchase of supplies for bathing and cleaning of boxes are essential aspects to minimize the environmental impact of this production. To accomplish this, it is necessary to strengthen the social link of communication among producers, workers, and veterinarians conducting 
workshops and training on the use and management of water on the farms and promoting good practices.

On the other hand, LCA methodology could be included in the studies of environmental impact that government authorities carry out on agricultural productions. This should be done so as to allow the points of conflict or of high environmental impact over which alternative solutions may be identified in the mid-to-long turn. Besides, production farms that promote this type of management could benefit from tax reductions or competitive advantages in the commercialization and export of animals in order for them to make the application of good practices a concrete goal for producers.

Author Contributions: Conceptualization, M.M.V. and A.V.V.; Methodology M.M.V. and A.V.V., Validation and sampling collected: A.G.-L.; Data curation, M.M.V.; Writing-original draft preparation, M.M.V. and A.V.V.; Supervision, funding acquisition A.F.-C. All authors have read and agreed to the published version of the manuscript.

Funding: This research was funded by Universidad de Buenos Aires and CONICET (PUE-INPA 22920180100047CO).

Data Availability Statement: The data belong to the Ph Thesis of M. M. Vaccaro and are available in the INPA repository.

Conflicts of Interest: The authors declare no conflict of interest.

\section{Appendix A}

Date.... . .... / . . . .

Form Number.........

Data confidentiality is guaranteed

Survey:

1. Equine farm profile

Place $\ldots \ldots \ldots \ldots$. . . . Coordinates . . . . . . . . . Route . . . . . . .

$\mathrm{Km} \ldots \ldots \ldots \ldots$...Quarter ... . . . . . Location . . . . . . . . . . . .

District ... . . . . . . . . . . . . Nearest Location . . . . . . . . . . . .

Head/Person in charge ......... .

Address

Phone number

1. Who provides advice for the nutritional management of your animals?

Veterinarian

Zootechnical Engineer

2. Which of the following do you use to feed your animals?

Alfafa forage

Bales

Pellets

Balanced food

3. Do you use supplementation?

-Concentrates

1. corn

2. oat

3. barley

-Oils

-Electrolytes

-Vitamins

-Growth promoters

4. How many hours a day do your animals spend in the box?

5 . What kind of bedding do they use?

Straw 


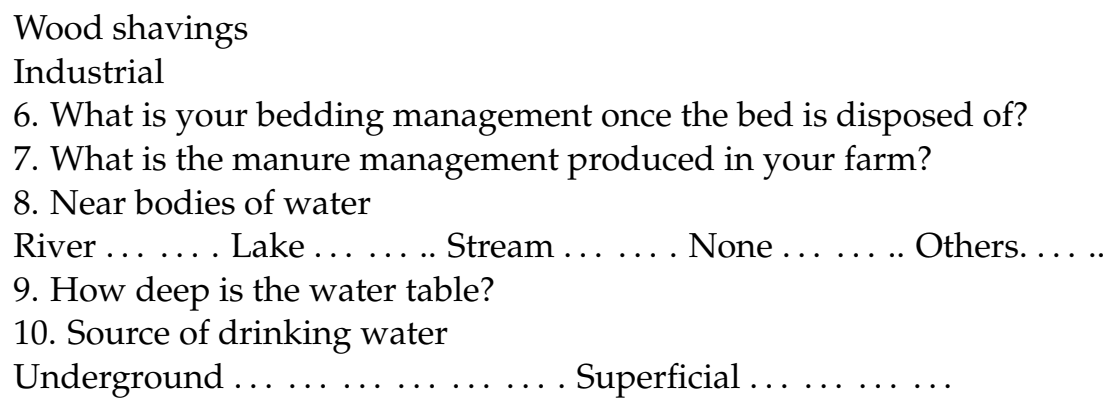

\section{References}

1. UNECLAC/UNW-DPAC. Water and a Green Economy in Latin America and the Caribbean (LAC); UNECLAC/UNW-DPAC: Santiago, Chile, 2012.

2. World Economic Forum. Global Risks 20165, 10th ed.; World Economic Forum: Geneva, Switzerland, 2016.

3. Amore, L. The United Nations World Water Development Report-N 4-Groundwater and Global Change: Trends, Opportunities and Challenges; Unesco: Paris, France, 2012; Volume 1.

4. UN. 2021 State of the World's Hand Hygiene Report. 2021. Available online: https://www.unwater.org/ (accessed on 15 July 2021).

5. Zamagni, A. Life cycle sustainability assessment. Int. J. Life Cycle Assess. 2012, 17, 373-376. [CrossRef]

6. Falcone, P.M.; Imbert, E. Social Life Cycle Approach as a Tool for Promoting the Market Uptake of Bio-Based Products from a Consumer Perspective. Sustainability 2018, 10, 1031. [CrossRef]

7. Boulay, A.M.; Bare, J.; Benini, L.; Berger, M.; Lathuillière, M.J.; Manzardo, A.; Pfister, S. The WULCA consensus characterization model for water scarcity footprints: Assessing impacts of water consumption based on available water remaining (AWARE). Int. J. Life Cycle Assess. 2018, 23, 368-378. [CrossRef]

8. Martínez, A.; Chargoy, J.; Puerto, M.; Suppen, N.; Rojas, D. Huella de Agua (ISO 14046) en América Latina, Análisis y Recomendaciones para una Coherencia Regional; Centro de Análisis de Ciclo de Vida y Diseño Sustentable CADIS, Embajada de Suiza en Colombia, Agencia Suiza para la Cooperación y el Desarrollo COSUDE: Bogota, Colombia, 2016; p. 90.

9. Martínez-Arce, A.; Chargoy, J.P.; Puerto, M.; Rojas, D.; Suppen, N. Water Footprint (ISO 14046) in Latin America, state of the art and recommendations for assessment and communication. Environments 2018, 5, 114. [CrossRef]

10. Hoekstra, A.Y. Virtual water: An introduction. Virtual Water Trade 2003, 13, 108.

11. Hooda, P.S.; Edwards, A.C.; Anderson, H.A.; Miller, A.A. Review of wáter quality concerns in livestock farming areas. Sci. Total Environ. 2000, 250, 143-167. [CrossRef]

12. Burgess, B.A.; Lohmann, K.L.; Blakley, B.R. Excessive sulfate and poor wáter quality as a cause of sudden deaths and an outbreak of diarrhea in horses. Can. Vet. J. 2010, 51, 267-277.

13. Parvage, M.M.; Ulén, B.; Kirchmann, H. Are horse paddocks threatening water quality through excess loading of nutrients J. Environ. Manag. 2015, 147, 306-313. [CrossRef] [PubMed]

14. Spore, T.J.; Mekonnen, M.M.; Neale, C.M.; Watson, A.K.; MacDonald, J.C.; Erickson, G.E. Evaluation of the water footprint of beef cattle production in Nebraska. Nebraska Beef Cattle Reports. 2020. Available online: https://digitalcommons.unl.edu/ animalscinbcr/1071/ (accessed on 20 July 2021).

15. Legesse, G.; Ominski, K.H.; Beauchemin, K.A.; Pfister, S.; Martel, M.; McGeough, E.J.; McAllister, T.A. Quantifying water use in ruminant production. J. Anim. Sci. 2017, 95, 2001-2018. [PubMed]

16. Westerndorf, M.L. Environmetal Impacts of equine Operations: AU.S Departament of A Multiste Proyects agricultura. J. Equine Vet. Sci. 2012, 32, 324-326. [CrossRef]

17. Mekonnen, M.M.; Hoekstra, A.Y. A global assessment of the water footprint of farm animal products. Ecosystems 2012, 15, 401-415. [CrossRef]

18. Baldini, C.; Gardoni, D.; Garino, M. A critical review of the recent evolution of Life Cycle assessment applied to milk production. J. Clean. Prod. 2007, 140, 421-435. [CrossRef]

19. Vaccaro, M.-M.; Garcia-Liñeiro, A.; Fernández-Cirelli, A. Management of Equine production and its environmental impact: The case of settlements in Buenos Aires (Argentina). Sustain. Agric. Food Environ. Res. 2017, 5, 17-24. [CrossRef]

20. Vaccaro, M.M.; Volpedo, A.V.; Liñeiro, A.G.; Cirelli, A.F. Water quality in equine production in Buenos Aires Province, Argentina. SN Appl. Sci. 2020, 2, 1-7. [CrossRef]

21. Gestión Ambiental-Huella de Agua-Principios, Requisitos y Directrices Environmental Management-Water FootprintPrinciples, Requirements and Guidelines. ISO 14046:2014(es). Available online: https://www.iso.org/standard/43263.html (accessed on 15 July 2021).

22. Klein, B.G. Cunningham. Fisiología Veterinaria, 5th ed.; Elsevier: Barcelona, España, 2014; p. 680.

23. APHA, AWWA, WPCF Métodos Normalizados Para el Análisis de Aguas Potables y Residuales, 22nd ed.; Díaz de Santos, S.A: Barcelona, España, 2002; p. 1816. 
24. Sollenberger, L.E.; Vanzant, E.S. Interrelationships among forage nutritive value and quantity and individual animal performance. Crop. Sci. 2011, 51, 420-432. [CrossRef]

25. Nemecek, T.; Bengoa, X.; Lansche, J.; Roesch, A.; Faist-Emmenegger, M.; Rossi, V.; Riedener, E. World Food LCA Database project: Towards more accurate food datasets. In Proceedings of the 6th International Conference on Life Cycle Management (LCM 2013), Gothenburg, Sweden, 25-28 August 2013.

26. Fernández Cirelli, A.; Moscuzza, H.; Pérez Carrera, A.; Volpedo, A.V. Aspectos Ambientales de Las Actividades Agropecuarias; Agrovet: Buenos Aires, Argentina, 2010; p. 189.

27. Asano, R.; Suzuki, K.; Otsuka, T.; Otsuka, M.; Sakurai, H. Concentrations of toxic metals and essential minerals in the main hair of healthy racing horses and their relation to age. J. Vet. Med. Sci. 2002, 64, 607-610. [CrossRef] [PubMed]

28. Smedley, P.; Kinninburgh, D. A review of the source, behaviour and distribution of arsenic in natural waters. Appl. Geochem. 2002, 17, 517-568. [CrossRef]

29. Farías, S.S.; Casa, V.A.; Vázquez, C.; Ferpozzi, L.; Pucci, G.N.; Cohen, I.M. Natural contamination with arsenic and other trace elements in ground waters of Argentine Pampean Plain. Sci. Total. Environ. 2003, 309, 187-199. [CrossRef]

30. CCME Canadian Environmental Quality Guidelines CEQFs. Available online: http://ceqgrcqe.ccme.ca/en/index.html (accessed on 15 August 2021).

31. United States Environmental Protection Agency. USEPA Water Quality Guidelines. Available online: https: / www.epa.gov / laws-regulations/regulations (accessed on 15 August 2021).

32. Basigalupo, D.H. El Cultivo de la Alfalfa en la Argentina; Ediciones INTA: Buenos Aires, Argentina, 2007; p. 479. ISBN 978-987-521242-8.

33. SMN. Servicio Meteorológico Nacional. 2021. Available online: https://www.smn.gob.ar/clima/tendencias (accessed on 15 August 2021).

34. Bongiovanni, R.G.; Anschau, R.A. Water footprint of alfalfa hay production in Córdoba, Argentina. In Proceedings of the Second World Alfalfa Congress, Cordoba, Argentina, 11-14 November 2018; Available online: http:/ /www.worldalfalfacongress.org/ (accessed on 15 August 2021).

35. Chapagain, A.K.; Hoekstra, A.Y. Water Footprints of Nations. Value of Water Research Report Series; UNESCO-IHE: Delft, The Netherlands, 2004; Available online: http:/ / www.waterfootprint.org/Reports/Report16.pdf (accessed on 15 August 2021).

36. FAO. Maize Crop Water Management; FAOSTAT: Rome, Italy, 2002.

37. Della Maggiora, A.I.; Gardiol, J.M.; Irigoyen, A.I. Requerimientos hídricos. In Bases Para el Manejo del Maíz, el Girasol y la Soja; Andrade, F.E., Sadras, V.O., Eds.; Editorial Médica Panamericana SA: Madrid, España, 2000; pp. 430-443. ISBN 987-521-016-1.

38. Mekonnen, M.M.; Hoekstra, A.Y. Daugherty Water for Food Global Institute: Faculty Publications. The Green, Blue and Grey Water Footprint of Farm Animals and Animal Products. Volume 2: Appendices. 2010. Available online: https://digitalcommons. unl.edu/wffdocs/82 (accessed on 20 August 2021). 